\title{
Impact on healthcare resource utilization of multiple sclerosis in Spain
}

\author{
Antoni Sicras-Mainar ${ }^{1}$, Elena Ruíz-Beato ${ }^{2}$, Ruth Navarro-Artieda ${ }^{3}$ and Jorge Maurino ${ }^{4,5^{*}}$
}

\begin{abstract}
Background: Multiple sclerosis (MS) is a chronic disease with a high socioeconomic impact. The aim of this study was to assess healthcare resources utilization and costs in a sample of patients with MS.

Methods: A retrospective, cohort study was conducted using electronic medical records from 19 primary care centres in Asturias and Catalonia, Spain. Adult patients diagnosed with MS were distributed into two groups according to the Expanded Disability Status Scale (EDSS) score: 0-3.5 (no-moderate disability) and 4-9.5 (severe disability). Healthcare (direct cost) and non-healthcare costs (work productivity losses) were analysed. An analysis of covariance (ANCOVA) was used for correction, $p<0.05$. A multiple regression model was performed to obtain the variables associated with costs.

Results: A total of 222 patients were analyzed; mean (SD) age: 45.5 (12.5) years, 64.4\% female, and 62.2\% presented a diagnosis of relapsing-remitting MS. Median EDSS score was 2.5, with $68.5 \%$ of the patients with no to moderate disability. The mean annual cost per MS patient was $€ 25,103$. For no-moderate and severe disability, the ANCOVAadjusted mean annual cost was $€ 23,157$ and $€ 29,242$, respectively $(p=0.013)$. Direct costs and MS disease-modifying therapy accounted for $39.4 \%$ and $31.7 \%$ of the total costs, respectively. The total costs were associated with number of relapses $(\beta=0.135, p=0.001)$, time since diagnosis $(\beta=0.281, p=0.023)$, and age $(\beta=0.198, p=0.037)$.
\end{abstract}

Conclusions: Multiple sclerosis imposes a substantial economic burden on the Spanish National Health System, patients and society as a whole. Costs significantly correlated with disease progression.

Keywords: Multiple sclerosis, Healthcare resource utilization, Costs, Electronic medical records

\section{Background}

Multiple sclerosis (MS) is a chronic, autoimmune disease characterised by inflammation of the central nervous system that leads to demyelination, axonal loss and progressive neuronal degeneration [1]. A prevalence of 125 cases/100,000 inhabitants was found in Spain affecting mainly young adults [2-5].

Multiple sclerosis progresses from episodic attacks followed by periods of remission (relapsing-remitting MS [RRMS]) to a more progressive state (secondary progressive MS [SPMS]) in approximately $80 \%$ of patients [1]. Primary progressive MS (PPMS) accounts for $10 \%$ of the overall population with MS and differs from RRMS and SPMS patients, in that progression consists of gradual worsening of neurologic disability from symptom onset [1]. Disease progression is linked to the

\footnotetext{
* Correspondence: jorge.maurino@roche.com

${ }^{4}$ Medical Department, Roche Farma, Madrid, Spain

${ }^{5}$ Madrid, Spain

Full list of author information is available at the end of the article
}

accumulation of disability, which overall, is faster for patients with PPMS than for patients with RRMS [1]. Current MS disease-modifying therapies (DMTs) are used with the aim of reducing the number of relapses, their severity, and slowing the disability's progression [6].

The age of onset of MS is generally in the most financially productive time of the patients' lives and consequently has a substantial economic burden on patients, their families, and society as a whole [7-10]. The European total annual cost of MS was $€ 14.6$ billion in 2010 (1.8\% of the total annual economic cost of all brain disorders) [11]. A recent study involving 16,808 patients with MS in 16 European countries found that work capacity of MS patients declined from 82 to $8 \%$ with advancing disease, and utility declined from normal population values to less than zero [12]. Patients with PPMS present higher healthcare utilization than patients with SPMS and RRMS, due to different provider visits, emergency visits, and hospital admissions [13]. Disease- 
modifying therapies are the main cost drivers for patients with mild disease severity, while for those with more advanced disability these are production losses and informal care [10, 12].

Mental and neurological disorders also have a substantial economic impact in Spain (equivalent to almost 8\% of the country's GDP) with a mean yearly per-patient cost of $€ 30,050$ for MS patients [14, 15]. However, information about the use of healthcare resources and associated costs among patients with MS in Spain is limited. The objective of this study was to assess the healthcare resources utilization of MS patients in Spain according to the degree of disability in order to provide detailed and updated information about the economic burden of the disease.

\section{Methods}

\section{Study design}

This study was a secondary analysis of electronic health records from 19 primary care centres in two regions of Spain (Asturias and Catalonia). The investigational review board of the Fundació Unió Catalana d'Hospitals (Barcelona) approved the protocol.

\section{Study population}

Key inclusion criteria were: age $\geq 18$ years, a diagnosis of MS (International Classification of Primary Care and International Statistical Classification of Diseases, ninth revision criteria), requiring medical care from 2010 to 2015 , and being in the long-term prescriptions program with a follow-up of $\geq 2$ records in the computer system $[16,17]$.

\section{Disability assessment}

The Expanded Disability Status Scale (EDSS) is a clinician-administered scale that is.

widely used in both clinical trials and routine clinical practice to assess the clinical severity and the functional impairment of MS [18]. The score is based on measures of impairment in eight functional systems: pyramidal, cerebellar, brainstem, sensory, bowel and bladder function, visual function, cognition, and 'other'. Each functional system is scored on a scale of 0 (no disability) to 5 or 6 (severe disability). The overall EDSS score ranges from 0 to 10 with higher scores indicating increased levels of disability.

\section{Demographic and clinical variables}

The following demographic and clinical variables were collected: age, gender, type of MS (RRMS, PPMS, SPMS and clinically isolated syndrome [CIS]), time since diagnosis, comorbidity and pharmacological treatments using the Anatomical Therapeutic Chemical
Classification System (ATC) [19]. The number of chronic diseases, the Charlson Comorbidity Index, and Case-mix Index obtained from the Adjusted Clinical Groups (ACG) were used to summarize general comorbidity [20,21].

\section{Healthcare resources and costs}

Direct healthcare costs were those related to healthcare activity (medical visits, hospitalisation days, emergency visits, diagnostic or therapeutic procedures and medication) and indirect costs related to work productivity loss (days off work due to sick leave). The cost was expressed as mean cost per patient (annual mean). Healthcare resources $(€$, year 2014) are shown in Table 1 and are expressed as mean cost per patient (cost/unit). The unit costs were obtained directly from the study centres with the exception of medication costs and work productivity loss. Prescriptions (acute, chronic, or upon request) were quantified according to the recommended retail price per package at the time of prescription (Bot Plus database) [22]. The days absent from work were collected from a specific computer program managed by primary care physicians and quantified according to the official minimum wage salary (source: Instituto Nacional de Estadistica-INE, Spanish National Statistics Institute) [23]. A sub-analysis of resource was performed in patients stratified by type of MS (RRMS vs. PPMS) using the above calculations.

\section{Statistical analysis}

Demographic, clinical and economic variables were collected for the overall sample of valid patients and for stratified subgroups according to the EDSS score: no

Table 1 Use of healthcare resources and unit costs

\begin{tabular}{ll}
\hline & Unit costs (EUR) \\
\hline Medical visits & 23.19 \\
Primary care & 117.53 \\
Emergency care & 320.90 \\
Hospitalisation (one day) & 67.50 \\
Special care & \\
Additional tests & \\
Laboratory tests & 22.30 \\
Conventional radiology tests & 18.50 \\
Other diagnostic/therapeutic tests & 47.12 \\
Pharmaceutical prescription & Retail price/pack \\
Work productivity-indirect costs & \\
Cost per day of sick leave & 79.4 \\
\hline
\end{tabular}

Source of healthcare resources: own analytical accounts and INE. Values expressed in euros (year 2014). Retail price includes value-added tax. ${ }^{a}$ Neurology visits 
disability -moderate disability $(0.0-3.5)$ and severe disability (4.0-9.5). A descriptive analysis was presented for all variables of interest with mean values, standard deviation (SD) and 95\% confidence intervals (CIs). Normal data distribution was verified using a KolmogorovSmirnov test. Costs were compared by analysis of covariance (ANCOVA) of age, gender, RUBs, Charlson Comorbidity Index, and time since MS diagnosis (generalized linear model). The bivariate analysis included ANOVA, the chi-squared test, Pearson's linear correlation, and comparison of means. A multiple linear regression model was used to evaluate the variables associated to the costs (stepwise method) including age, gender, RUBs, Charlson Comorbidity Index, time since MS diagnosis, and EDSS score. The Statistical Package for the Social SciencesWindows (SPSSWIN) version 19 was used. A $p$-value $<0.05$ was considered to be statistically significant.

\section{Results}

A total of 222 patients were included (Figure 1). The mean (SD) age was 45.5 (12.5) years and $64.4 \%$ were female. Prevalence of MS was 71 cases/100,000 inhabitants. Relapsing-remitting MS was the most common clinical form $(62.2 \%$ of the patients). The median EDSS score was 2.5 (range: 1.0-8.5). The impact of comorbidity was significantly greater in the severe disability group vs. the no to moderate disability group: mean number of comorbidities (6.0 vs. 4.5; $p=0.001)$, Charlson Index (1.0 vs. 0.7; $p=0.005)$, and RUBs (3.2 vs. $2.9 ; p=0.003)$. Demographic and clinical characteristics of the patients are shown in Table 2. Intramuscular interferon beta-1a (30.6\%), subcutaneous interferon beta-1a (23.9\%) and glatiramer acetate $(18 \%)$ were the most common diseasemodifying treatments administered.

\section{Healthcare resource use}

Table 3 shows the mean annual use of healthcare resources by each disability group. Patients in the severe disability group, presented a significantly higher number of primary care medical visits $(12.3$ vs. $8.5 ; p<0.001)$, specialised medical visits (3.0 vs. $2.3 ; p=0.008$ ), emergency room visits $(2.0$ vs. $1.2 ; \mathrm{p}<0.001)$, and hospitalisation days (5.6 vs. 1.3 days; $\mathrm{p}<0.001$ ) compared to patients in the no-moderate disability group. Mean (SD) work productivity losses were also significantly higher for the severe disability group vs. to the no-moderate disability group: 258.1 (162.0) vs. 160.9 (173.4) days, $p<0.001$, respectively.

Patients with PPMS showed a significantly higher frequency of additional tests use (other than laboratory and radiology tests), days of hospitalisations (both $p \leq 0.001)$, radiological tests use $(p=0.001)$, and specialised medical visits $(p=0.012)$ compared to RRMS patients (Table 4).

\section{Direct healthcare costs and indirect costs}

Table 5 specifies the direct healthcare costs and indirect costs (unadjusted and adjusted values) by disability group. From the total costs, $34.7 \%$ were related to primary care and $4.8 \%$ to specialised care. Disease-modifying therapies accounted for $31.7 \%$ of the total cost.

The total cost for the 222 study patients was 5.6 million euros, $39.4 \%$ of which were direct healthcare costs. The total annual mean cost (direct and indirect) per MS patient was $€ 25,103$. This mean cost was significantly higher in the severe disability (vs. no-moderate disability) group $(€ 31,608$ vs. $€ 22,107 p<0.001)$, predominantly due to a higher healthcare resource utilization, in particular primary care visits $(12.3$ vs. $8.5 ; \mathrm{p}<0.001)$.

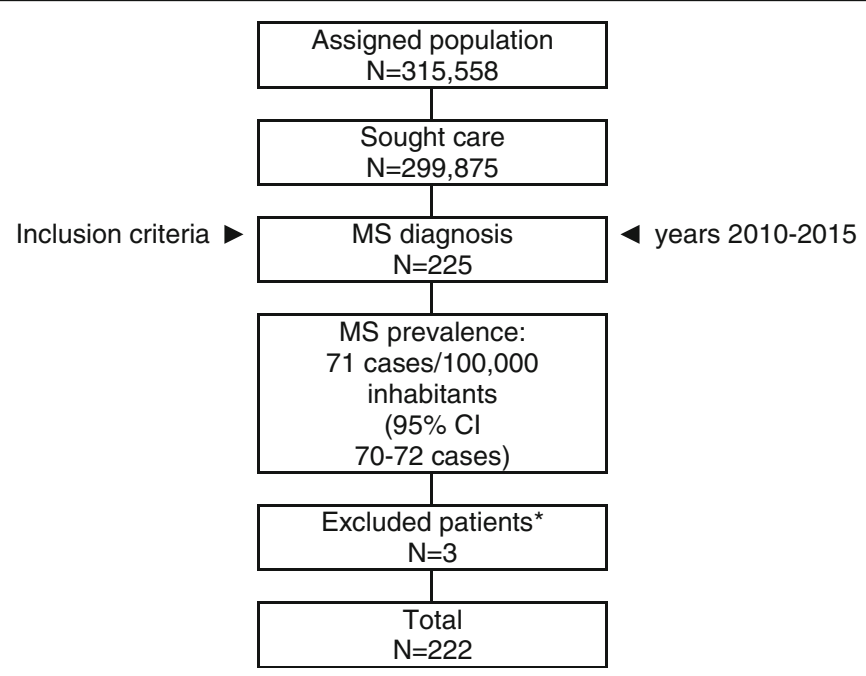

Fig. 1 Study disposition. *Patients were excluded due to missing or inconsistent data $(n=2)$ and loss of follow-up $(n=1)$. MS: Multiple Sclerosis 
Table 2 Demographic and clinical characteristics

\begin{tabular}{lllll}
\hline & $\begin{array}{l}\text { EDSS 0-3.5 } \\
N=152\end{array}$ & $\begin{array}{l}\text { EDSS 4.0-9.5 } \\
N=70\end{array}$ & $\begin{array}{l}\text { Total } \\
N=222\end{array}$ & $p$-value \\
& & & & \\
\hline $\begin{array}{l}\text { Geographic regions } \\
\text { in Spain, \% }\end{array}$ & & & & \\
$\quad$ Asturias & 30.9 & 22.9 & 28.4 & 0,587 \\
$\quad$ Catalonia & 69.1 & 77.1 & 71.6 & 0,827 \\
Age, years, mean (SD) & $42.5(11.5)$ & $52.2(12.2)$ & 45.5 & $<0.001$ \\
& & & $(12.5)$ & \\
Gender, female, N (\%) & 68.4 & 65.7 & 64.4 & 0.292 \\
Time since diagnostic, & $10.5(7.6)$ & $19.8(10.2)$ & $13.4(9.5)$ & $<0.001$ \\
years, mean (SD) & & & & \\
MS type, \% & & & & \\
$\quad$ RRMS & 74.3 & 35.7 & 62.2 & $<0.001$ \\
$\quad$ SPMS & 13.8 & 50.0 & 25.2 & $<0.001$ \\
PPMS & 7.2 & 14.3 & 9.5 & 0.009 \\
CIS & 4.6 & 0.0 & 3.2 & $<0.001$
\end{tabular}

Relapses during

follow-up

Number of relapses, $\quad 0.4(0.6) \quad 1.2(1.0) \quad 0.7(0.9) \quad<0.001$ mean (SD)

Proportion of population, N (\%)

$\begin{array}{lllll}\geq 1 & 36.8 & 67.1 & 46.4 & <0.001 \\ 1 & 29.6 & 18.6 & 26.1 & 0.008 \\ 2 & 6.6 & 40.0 & 17.1 & <0.001 \\ 3 & 0.7 & 8.6 & 3.2 & 0.790 \\ \begin{array}{l}\text { Comorbidity, mean (SD) } \\ \quad\end{array} & & & \\ \begin{array}{l}\text { Number of } \\ \text { Comorbidities } \\ \text { Charlson Index }\end{array} & 0.5(2.7) & 6.0(3.3) & 5.0(3.0) & 0.001 \\ \text { RUBs, mean } & 0.7(0.6) & 1.0(0.7) & 0.8(0.6) & 0.005 \\ & 2.9(0.8) & 3.2(0.7) & 3.0(0.8) & 0.003\end{array}$

Proportion of population,

N (\%)

\begin{tabular}{lllll}
1 (healthy o very low & 3.3 & 0.0 & 2.3 & $<0.001$ \\
morbidity) & & & & \\
2 (low morbidity) & 25.7 & 14.3 & 22.1 & 0.038 \\
$\begin{array}{l}\quad \text { (moderate } \\
\text { morbidity) }\end{array}$ & 52.0 & 54.3 & 52.7 & 0.873 \\
$\quad 4$ (high morbidity) & 18.4 & 28.6 & 21.6 & 0.041 \\
$\begin{array}{l}\quad \text { (very high } \\
\text { morbidity) }\end{array}$ & 0.7 & 2.9 & 1.4 & 0.031 \\
\hline
\end{tabular}

CIS clinically isolated syndrome, EDSS expanded disability status scale, MS multiple sclerosis, PPMS primary progressive MS, RRMS relapsing remitting MS, RUBs resource utilization bands, SD standard deviation, SPMS secondary-progressive MS

In the adjusted model (ANCOVA) this mean (95\% CI) difference in total cost was maintained: severe disability $€ 29,242 \quad(€ 25,467, € 33,016)$ vs. no-moderate disability $€ 23,157$ ( $€ 20,561, € 25,753)$; a statistically significant difference of approximately $€ 6085$ was observed ( $p=0.013$ ). In the multiple regression model, the total costs were
Table 3 Healthcare resource use and costs

\begin{tabular}{|c|c|c|c|c|}
\hline & EDSS 0-3.5 & EDSS 4.0-9.5 & Total & $p$-value \\
\hline & $N=152$ & $N=70$ & $N=222$ & \\
\hline Annual number per $\mathrm{p}$ & ient, mean ( $\mathrm{S}$ & & & \\
\hline $\begin{array}{l}\text { Medical visits, } \\
\text { primary care }\end{array}$ & $8.5(5.7)$ & $12.3(5.7)$ & $9.7(6.0)$ & $<0.001$ \\
\hline $\begin{array}{l}\text { Medical visits, } \\
\text { specialists }\end{array}$ & $2.3(1.5)$ & $3.0(2.0)$ & $2.5(1.7)$ & 0.008 \\
\hline Laboratory tests & $2.8(2.6)$ & $3.7(2.7)$ & $3.1(2.7)$ & 0.010 \\
\hline Radiology tests & $1.9(2.5)$ & $3.2(2.6)$ & $2.3(2.6)$ & $<0.001$ \\
\hline Additional tests & $1.6(2.3)$ & $3.4(3.8)$ & $2.2(3.0)$ & $<0.001$ \\
\hline Hospitalisation days & $1.3(3.8)$ & $5.6(6.7)$ & $2.7(5.3)$ & $<0.001$ \\
\hline ER visits & $1.2(1.3)$ & $2.0(1.5)$ & $1.5(1.4)$ & $<0.001$ \\
\hline $\begin{array}{l}\text { Work productivity } \\
\text { losses, days }\end{array}$ & $\begin{array}{l}160.9 \\
(173.4)\end{array}$ & $258.1(162.0)$ & $\begin{array}{l}191.6 \\
(175.5)\end{array}$ & $<0.001$ \\
\hline
\end{tabular}

EDSS Expanded Disability Status Scale, ER emergency room, SD standard deviation

associated to the number of relapses $(\beta=0.135,95 \% \mathrm{CI}$ $10.2-105.1, p=0.001)$, time since diagnosis $(\beta=0.281$, 95\% CI -272.2-11.8, $p=0.023)$ and age $(\beta=0.198,95 \% \mathrm{CI}$ $3.1-195.2, p=0.037)$. The EDSS score was included in the model but was not significant. The model's coefficient of determination was $33.5 \%$. There were no significant differences between the evaluated variables by geographical regions. It is worth noting that $50.5 \%$ of the patients in the whole sample were unemployed due to their disability.

\section{Discussion}

Multiple sclerosis is a chronic disabling disease that is associated with reduced quality of life and a high socioeconomic impact [7]. Physical disability at diagnosis is the main determinant of the economic burden, with $13 \%$ increased annual costs for each additional point from baseline EDSS [24]. In addition, the costs increase with more

Table 4 Healthcare resource use and costs according to MS type

\begin{tabular}{lllll}
\hline & RRMS & PPMS & Total & $p$-value \\
& $N=152$ & $N=70$ & $N=222$ & \\
\hline Annual number per patient, mean (SD) & & \\
$\begin{array}{l}\text { Medical visits, } \\
\text { primary care }\end{array}$ & $8.9(5.9)$ & $10.0(7.1)$ & $9.1(6.0)$ & 0.426 \\
$\begin{array}{l}\text { Medical visits, } \\
\text { specialists }\end{array}$ & $2.3(1.6)$ & $3.3(1.7)$ & $2.4(1.7)$ & 0.012 \\
Laboratory tests & $2.9(2.8)$ & $3.3(1.8)$ & $3.0(2.7)$ & 0.589 \\
Radiology tests & $1.6(2.0)$ & $3.3(2.2)$ & $1.8(2.1)$ & 0.001 \\
Additional tests & $1.7(2.6)$ & $4.6(4.1)$ & $2.1(3.0)$ & $<0.001$ \\
Hospitalisation days & $1.4(4.0)$ & $5.4(6.3)$ & $1.9(4.6)$ & $<0.001$ \\
Hospital emergencies & $1.3(1.3)$ & $1.7(1.8)$ & $1.4(1.4)$ & 0.237 \\
$\begin{array}{l}\text { Work productivity losses, } \\
\text { days }\end{array}$ & 177 & 123.3 & 169.9 & 0.190 \\
\hline MS multiple sclerosis, PPMS & $(174.1)$ & $(175.2)$ & $(174.7)$ & \\
\hline
\end{tabular}

MS multiple sclerosis, PPMS primary progressive MS, RRMS relapsing remitting MS, SD standard deviation 
Table 5 Direct healthcare and indirect annual costs per MS patient (in EUR) according to disability level

\begin{tabular}{|c|c|c|c|c|}
\hline & EDSS 0-3.5 & EDSS 4.0-9.5 & Total & $P$-value \\
\hline & $N=152$ & $N=70$ & $N=222$ & \\
\hline Unadjusted costs & & & & \\
\hline Annual cost $(€)$ per patient, & $\operatorname{an}(S D)$ & & & \\
\hline Direct healthcare costs & $9331.7(5504.5)$ & $11,112.2(6649.9)$ & $9893.2(5932.7)$ & 0.037 \\
\hline Primary care & 8614.7 (5199.4) & $8887.5(6178.4)$ & $8700.7(5514.1)$ & 0.733 \\
\hline Medical visits & $197.0(132.9)$ & $285.6(131.6)$ & $224.9(138.5)$ & $<0.001$ \\
\hline Lab tests & $61.3(59.0)$ & $83.5(59.6)$ & $68.3(60.0)$ & 0.010 \\
\hline Conventional radiology & $34.6(45.6)$ & $59.7(48.0)$ & $42.5(47.8)$ & $<0.001$ \\
\hline Supplementary tests & $75.3(110.5)$ & $158.2(181.4)$ & $101.5(141.8)$ & $<0.001$ \\
\hline Medication & $272.8(173.4)$ & $417.6(193.1)$ & $318.5(191.6)$ & $<0.001$ \\
\hline MS-specific drugs & 7973.7 (5196.7) & $7882.9(6186.7)$ & $7945.0(5514.0)$ & 0.910 \\
\hline Specialised care & $717.0(1361.2)$ & $2224.7(2342.7)$ & $1192.5(1863.5)$ & $<0.001$ \\
\hline Hospitalisations & $418.0(1211.5)$ & $1792.5(2147.8)$ & $851.4(1689.0)$ & $<0.001$ \\
\hline Medical visits & $156.8(102.4)$ & $200.6(134.0)$ & $170.6(114.8)$ & 0.008 \\
\hline Emergency room visits & $142.3(156.9)$ & $231.7(180.1)$ & $170.5(169.4)$ & $<0.001$ \\
\hline Indirect costs ${ }^{\mathrm{a}}$ & $12,775.0(13,768.9)$ & $20,495.4(12,862.0)$ & $15,209.4(13,932.3)$ & $<0.001$ \\
\hline Total costs & $22,106.8(15,313.8)$ & $31,607.6(14,435.0)$ & $25,102.5(15,648.1)$ & $<0.001$ \\
\hline Adjusted costs ${ }^{\mathrm{b}}$ & & & Difference between unadjusted and adjusted costs & \\
\hline Annual cost $(€)$ per patient, & $\operatorname{ann}(95 \% \mathrm{Cl})$ & & & \\
\hline Direct Healthcare costs & $9124(8100,10,147)$ & $11,476(9988,12,963)$ & 2352 & 0.015 \\
\hline Primary care & $8331(7364,9296)$ & $9477(8072,10,881)$ & 1146 & 0.205 \\
\hline Specialised care & $793(499,1087)$ & $1999(1571,2426)$ & 1206 & $<0.001$ \\
\hline Indirect costs (productivity) & $14,033(11,715,16,351)$ & $17,766(14,395,21,136)$ & 3733 & 0.049 \\
\hline Total costs & $23,157(20,561,25,753)$ & $29,242(25,467,33,016)$ & 6085 & 0.013 \\
\hline
\end{tabular}

95\% Cl 95\% confidence interval, EDSS expanded disability status scale, SD standard deviation. ${ }^{\text {Indirect }}$ costs: loss of work productivity. ${ }^{\mathrm{b}}$ ANCOVA model: costs adjusted by covariables (age, gender, resource utilization bands [RUBs], Charlson comorbidity index, and time since diagnosis of the multiple sclerosis)

severe disability, especially when patients lose their upper limb function and independence (EDDS score > 7.0) [25].

The therapeutic landscape of treatment has changed dramatically over the last years. An increasing number of new drugs have recently shown encouraging results for the management of RRMS due to their proven higher efficacies compared to first-generation DMTs [6]. However, despite the availability of more treatment options, costs for all DMTs have increased substantially [10]. In addition, the early disease onset of MS has a significant impact on the patient's most productive working years, leading to huge potential societal costs associated with this productivity loss [10]. Patients are less likely to be employed, are more likely to require time off work and to retire early compared to people without MS [7, 9, 12].

The impact on the costs of managing patients with MS is increasingly an area of interest [26-29]. However, comparing costs between countries with different socioeconomic, cultural, epidemiological background, and different systems for organizing and funding healthcare is very difficult $[12,30]$.
This study shows an overall annual mean cost per MS patient of $€ 25,103$. This mean cost was significantly higher in patients with severe disability compared than those with no-moderate disability ( $€ 29,242$ and $€ 23,157$, respectively; $p=0.013$ ). Total cost was associated to the number of relapses, time since diagnosis, and age $(p=0.001,0.023$, and 0.037 , respectively). Indirect costs and MS therapy accounted for $61 \%$ and $31.7 \%$ of the total costs, respectively.

In Spain, the available data for cost of MS is limited $[12,31-34]$. These findings concur with prior studies. In a cost-of-illness analysis based on information from 1848 patients, Kobelt et al. found that the total mean costs per patient were driven by the distribution of the disease severity levels [30]. Workforce participation decreased from approximately $70 \%$ in the early disease stages to less than $5 \%$ in the very late stages. Productivity losses increased more than eightfold in patients with an EDSS score of 0-1 vs. 8-9. In another study with a sample of 200 MS patients in Barcelona, Casado et al. found that the main drivers for direct costs were DMTs 
in low disability stages and caregiver costs in severe disability stages [32]. Overall, direct healthcare costs accounted for $60 \%$ of total cost; within these direct costs DMTs accounted for $78 \%$ in the early disability stages to $11 \%$ in the later disability stages. The correlation of disability with the increasing economic burden of MS was also shown in the TRIBUNE study [34]. The mean cost per patient per year was $€ 20,659$ for patients with mild disease severity, while patients with moderate MS incurred more than double that cost $(€ 43,948)$. DMTs were the most expensive cost component for patients with mild and moderate disability (58\% and $32 \%$, respectively) [34].

Missing values and differences on diagnostic codification are usual limitations related to studies with population databases [35]. McDonald 2010 criteria were not used in the study because our healthcare database collected diagnosis following only IPC-2 and ICD-9 classifications. In addition, concomitant medications were not evaluated. This study did not include any non-healthcare direct costs, classified as "out-of-pocket" costs paid by the patient/family, as they were not recorded in the database. The only direct costs considered were those relating to the public health system and the area of influence of the patient. Another limitation was the absence of informal caregivers to calculate informal costs. Sick leave (temporary or permanent) may in turn be a limited indicator of indirect costs as premature death and informal costs were not considered. In addition, standard cost for sick leave should have been applied, rather than the specific costs depending on patients' income. Despite these limitations, these results reflect the economic impact of MS and how these vary between different disability levels.

\section{Conclusions}

Patients with MS show high healthcare resource utilization and large work productivity losses that cumulatively impose a substantial economic burden on the healthcare system and society as a whole. This burden was enhanced upon disease progression.

Therefore, a more proactive management strategy, including earlier use of high-efficacy DMTs and close monitoring of the clinical and radiological response to treatment, is recommended to slow or halt the progression of physical and cognitive impairments in patients with MS [36, 37]. No evidence of disease activity is emerging as a new standard MS outcome and may be associated with improved long-term disability.

Additional research focusing on direct healthcare and indirect costs as well as standardised methodologies to calculate costs are necessary to determine the association between the disease evolution and economic burden.

\section{Abbreviations}

ACG: Adjusted clinical groups;; CIS: Clinically isolated syndrome;

EDSS: Expanded disability status scale; ICD-9: International statistical classification of diseases; IPC-2: International classification of primary care; MS: Multiple sclerosis; PPMS: Primary progressive multiple sclerosis; RRMS: Relapsing-remitting multiple sclerosis; RUBs: Resource utilization bands; SD: Standard deviation; SPMS: Secondary progressive multiple sclerosis

\section{Acknowledgements \\ None. \\ Funding \\ The study was funded by Roche Farma SA, Spain.}

\section{Availability of data and materials}

The dataset of the current study is available from the corresponding author on reasonable request.

\section{Author's contributions}

ASM, ERB, RNA and JM developed the research question. ASM designed the study, wrote the protocol and performed the statistical analyses. All authors contributed to and have approved the final manuscript.

Ethics approval and consent to participate

The study protocol was approved by the investigational review board of the Fundació Unió Catalana d'Hospitals (Barcelona, Spain).

Consent for publication

Not applicable.

\section{Competing interests}

ERB and JM are employees of Roche Farma SA. None of the other authors report any conflict of interest.

\section{Publisher's Note}

Springer Nature remains neutral with regard to jurisdictional claims in published maps and institutional affiliations.

\section{Author details}

${ }^{1}$ Fundación Rediss (Red de Investigación en Servicios Sanitarios), Barcelona, Spain. ${ }^{2}$ Health Economics and Outcomes Research Unit, Roche Farma, Madrid, Spain. ${ }^{3}$ Department of Medical Information, Hospital Universitari Germans Trias i Pujol, Badalona, Barcelona, Spain. ${ }^{4}$ Medical Department, Roche Farma, Madrid, Spain. ${ }^{5}$ Madrid, Spain.

Received: 3 July 2017 Accepted: 15 December 2017

Published online: 29 December 2017

\section{References}

1. Vidal-Jordana A, Montalban X. Multiple sclerosis: epidemiologic, clinical, and therapeutic aspects. Neuroimaging Clin N Am. 2017;27:195-204.

2. Howard J, Trevick S, Younger DS. Epidemiology of multiple sclerosis. Neurol Clin. 2016:34:919-39.

3. Otero-Romero S, Roura P, Solà J, Altimiras J, Sastre-Garriga J, Nos C, Vaqué J, Montalban X. Increase in the prevalence of multiple sclerosis over a 17-year period in Osona, Catalonia, Spain. Mult Scler. 2013;19:245-8.

4. Candeliere-Merlicco A, Valero-Delgado F, Martínez-Vidal S, Lastres-Arias MDC, Aparicio-Castro E, Toledo-Romero F, Villaverde-González R. Prevalence of multiple sclerosis in Health District III, Murcia, Spain. Mult Scler Relat Disord. 2016;9:31-5.

5. Fernández O, Fernández V, Guerrero M, León A, López-Madrona JC, Alonso A, Bustamante R, Tamayo JA, Romero F, Bravo M, Luque G, García L, Sanchís G, San Roman C, Romero M, Papais-Alvarenga M, de Ramon E. Multiple sclerosis prevalence in Malaga, southern Spain estimated by the capturerecapture method. Mult Scler. 2012;18:372-6.

6. Torkildsen $\varnothing$, Myhr K-M, Bø L. Disease-modifying treatments for multiple sclerosis - a review of approved medications. Eur J Neurol. 2016;23(Suppl 1):18-27.

7. Ayuso Gl. Multiple sclerosis: socioeconomic effects and impact on quality of life. Med Clínica. 2014;143(Suppl 3):7-12. 
8. Rivera-Navarro J, Benito-León J, Oreja-Guevara C, Pardo J, Dib WB, Orts E, et al. Burden and health-related quality of life of Spanish caregivers of persons with multiple sclerosis. Mult Scler. 2009;15:1347-55.

9. Bøe Lunde HM, Telstad W, Grytten N, Kyte L, Aarseth J, Myhr K-M, et al. Employment among patients with multiple sclerosis-a population study. PLoS One. 2014;9:e103317.

10. Ernstsson O, Gyllensten H, Alexanderson K, Tinghög P, Friberg E, Norlund A. Cost of illness of multiple sclerosis - a systematic review. PLoS One. 2016;11:e0159129.

11. Olesen J, Gustavsson A, Svensson M, Wittchen H-U, Jönsson B. CDBE2010 study group, et al. the economic cost of brain disorders in Europe. Eur J Neurol. 2012;19:155-62.

12. Kobelt G, Thompson A, Berg J, Gannedahl M, Eriksson J. New insights into the burden and costs of multiple sclerosis in Europe. Mult Scler. 2017;23:1123-36.

13. Salter A, Thomas NP, Tyry T, Cutter GR, Marrie RA. A contemporary profile of primary progressive multiple sclerosis participants from the NARCOMS registry. Mult Scler. 2017; [Epub ahead of print]

14. Parés-Badell O, Barbaglia G, Jerinic $P$, Gustavsson A, Salvador-Carulla L, Alonso J. Cost of disorders of the brain in Spain. PLoS One. 2014;9:e105471.

15. Fernández O, Calleja-Hernández MA, Meca-Lallana J, Oreja-Guevara C, Polanco A, Pérez-Alcántara F. Estimate of the cost of multiple sclerosis in Spain by literature review. Expert Rev Pharmacoecon Outcomes Res. 2017; 17:321-33.

16. Lamberts $\mathrm{H}$, Wood M, Hofmans-Okkes I. The international classification of primary Care in the European Community. With a multi-language layer. 2nd ed. Oxford: Oxford University Press; 1993.

17. ICD - ICD-9 - International Classification of Diseases, Ninth Revision [Internet]. [cited 2016 Nov 14]. Available from: http://www.cdc.gov/nchs/ icd/icd9.htm

18. Kurtzke JF. Rating neurologic impairment in multiple sclerosis: an expanded disability status scale (EDSS). Neurology. 1983;33:1444-52.

19. World Health Organization. The anatomical therapeutic chemical ATC classification system. Geneva: World Health Organization; 1991.

20. Charlson ME, Pompei P, Ales KL, MacKenzie CR. A new method of classifying prognostic comorbidity in longitudinal studies: development and validation. J Chronic Dis. 1987;40:373-83.

21. Weiner JP, Starfield BH, Steinwachs DM, Mumford LM. Development and application of a population-oriented measure of ambulatory care case-mix. Med Care. 1991:29:452-72

22. General Council of Official Colleges of Pharmacists. Bot Plus database. Botplusweb.portalfarma.com. BOT Plus 2. Base de Datos de Medicamentos [Internet]. [cited 2016 Nov 9]. Available from: https://botplusweb. portalfarma.com/

23. Instituto Nacional de Estadística. Encuesta de costes laborales del año 2014 [Internet]. 2011 [cited 2016 Oct 12]. Available from: http://www.ine.es/infoine

24. Moccia M, Palladino R, Lazillo R, Triassi M, Brescia Morra V. Predictors of the 10 year direct costs for treating multiple sclerosis. Acta Neurol Scand. 2017;135:522-8.

25. Giovannoni G. Can we afford not to prevent MS-related disability? Mult Scler. 2017:23:1048-9.

26. Adelman G, Rane SG, Villa KF. The cost burden of multiple sclerosis in the United States: a systematic review of the literature. J Med Econ. 2013;16:639-47.

27. Gyllesten H, Wiberg M, Alexanderson K, Norlund A, Friberg E, Hillert J, et al. Costs of illness of multiple sclerosis in Sweden: a population-based register study of people of working age. Eur J Health Econ. 2017; https://doi.org/10. 1007/s10198-017-0894-6. [Epub ahead of print].

28. Moccia M, Palladino R, Lazillo R, Carotenuto A, Russo CV, Triassi M, et al. Healthcare costs for treating relapsing multiple sclerosis and the risk of progression: a retrospective Italian cohort study from 2001 to 2015. PLoS One. 2017;12:e0169489.

29. Karampampa K, Gustavsson A, Miltenburger C, Eckert B. Treatment experience, burden and unmet needs (TRIBUNE) in MS study: results from five European countries. Mult Scler. 2012;18(2 Suppl):7-15.

30. Marziniak M, Ghorab K, Kozubski W, et al. Variations in multiple sclerosis practice within Europe - is it time for a new treatment guideline? Mult Scler Relat Disord. 2016:8:35-44.

31. Kobelt G, Berg J, Lindgren P, Izquierdo G, Sánchez-Soliño O, Pérez-Miranda J, et al. Costs and quality of life of multiple sclerosis in Spain. Eur J Health Econ. 2006;7(Suppl. 2):S65-74

32. Casado V, Martínez-Yélamos S, Martínez-Yélamos A, Carmona O, Alonso L Romero $L$, et al. Direct and indirect costs of multiple sclerosis in Baix Llobregat (Catalonia, Spain), according to disability. BMC Health Serv Res. 2006;6:143.
33. Casado V, Romero L, Gubieras L, Alonso L, Moral E, Martinez-Yelamos S, et al. An approach to estimating the intangible costs of multiple sclerosis according to disability in Catalonia, Spain. Mult Scler. 2007;13:800-4.

34. Karampampa K, Gustavsson A, Miltenburger C, Mora S, Arbizu T. Treatment experience, burden and unmet needs (TRIBUNE) in MS study: results from Spain. Mult Scler. 2012;18:35-9.

35. Motheral B, Brooks J, Clark MA, Crown WH, Davey P, Hutchins D, et al. A checklist for retrospective database studies-report of the ISPOR task force on retrospective databases. Value Health. 2003:6:90-7.

36. Duquette P, Giacomini PS, Bhan V, Hohol M, Schecter R. Balancing early aggression against risk of progression in multiple sclerosis. Can J Neurol Sci. 2016;43:33-43

37. Merkel B, Butzkueven H, Traboulsee AL, Havrdova E, Kalincik T. Timing of high-efficacy therapy in relapsing-remitting multiple sclerosis: a systematic review. Autoimmun Rev. 2017;16:658-65.

\section{Submit your next manuscript to BioMed Central and we will help you at every step:}

- We accept pre-submission inquiries

- Our selector tool helps you to find the most relevant journal

- We provide round the clock customer support

- Convenient online submission

- Thorough peer review

- Inclusion in PubMed and all major indexing services

- Maximum visibility for your research

Submit your manuscript at www.biomedcentral.com/submit
Biomed Central 